\title{
CORRECTION TO: IRON REDUCTION IN 356 SECONDARY ALUMINUM ALLOY BY Mn AND Cr ADDITION FOR SEDIMENT SEPARATION
}

\author{
Annadurai Dhinakar, Po-Yu Lu, and Jhewn-Kuang Chen $(1)$ \\ Institute of Materials Science and Engineering, National Taipei University of Technology, Taipei, Taiwan \\ Nai-Kuang Tang \\ Metal Industries Research and Development Centre, Kaohsiung, Taiwan
}

Copyright $(92020$ American Foundry Society

https://doi.org/10.1007/s40962-020-00458-7

\section{Correction to: \\ International Journal of Metalcasting \\ https://doi.org/10.1007/s40962-020-00433-2}

In the original version of this article, Annadurai Dhinakar's first and last names were transposed. The original article has been corrected.
Publisher's Note Springer Nature remains neutral with regard to jurisdictional claims in published maps and institutional affiliations. 